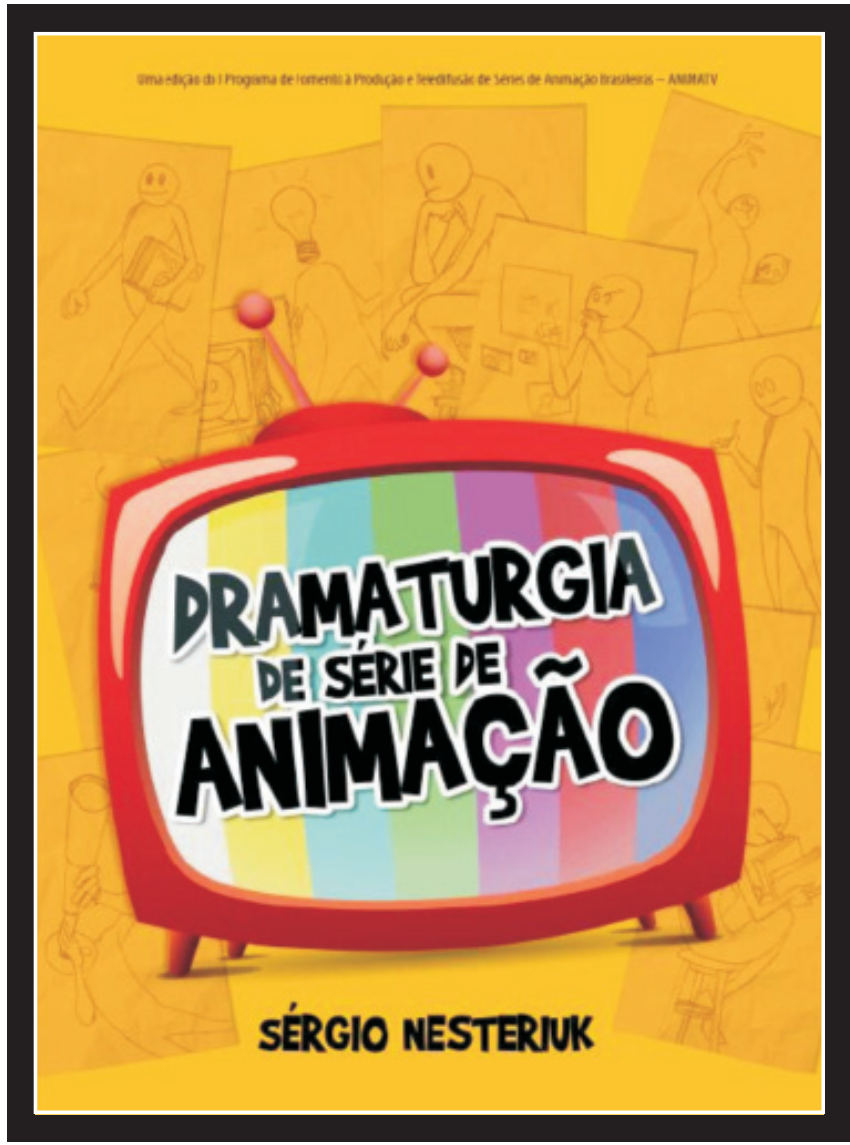

Dramaturgia de série de animação [recurso eletrônico], de Sérgio Nesteriuk. São Paulo, ANIMATV / Sérgio Nesteriuk, 2011, 300 p. 


\title{
Publicação gratuita fortalece a produção de animações brasileiras
}

Free publication strengthens Brazilian production of animations

\author{
Emerson S. Dias*
}

As produções brasileiras na área de animação (desenhos para televisão, curtas-metragens em stop motion e até mesmo peças publicitárias) vêm ganhando terreno mundo afora e fortalecendo pesquisas, projetos e parcerias com estúdios no exterior desde a virada do século XXI. O que começou com a Turma da Mônica nos anos 1980 (um período difícil para transpor roteiros e histórias em quadrinhos para cinema e TV) agora segue a passos largos e com periodicidade garantida em canais brasileiros (TV Cultura, TV Brasil e até mesmo na MTV) e estrangeiros (Discovery Kids, Cartoon Network e Nickelodeon). Detalhe: ao conquistar espaço nestas emissoras de TV a Cabo, os seriados ganham audiência (e dublagem) em várias partes do mundo.

Séries animadas como "Peixonauta", "Princesas do Mar", "Escola pra Cachorro", "As Aventuras de Gui \& Estopa", "Megaliga MTV de VJs Paladinos", "Fudêncio", "De Onde Vem?" e "Meu Amigãozão" são apenas alguns exemplos de produções que conquistaram o público dentro e fora do país pela originalidade e, claro, qualidade dos episódios. Ainda é pouco, se comparado à produção norte-americana, mas os índices são animadores.

Muitos fatores poderiam ser levantados para justificar a explosão das animações brasileiras, a começar pelos avanços tecnológicos que facilitam a vida de quem precisa dar movimento aos personagens (equipamentos e softwares diversos para desenhistas, montadores,

\footnotetext{
* Jornalista profissional desde 1998. Especialista em História e Sociedade pela Universidade Estadual de Maringá (UEM). Mestre em Ciências Sociais pela Universidade Estadual de Londrina (UEL). Professor na graduação em Comunicação Social (Jornalismo) e na pós-graduação (Especialização em Animação em Mídias Digitais) do curso de Design, ambas da UEL. E-mail: emerson.dias@gmail.com
} 
animadores e editores). No entanto, vale destacar dois pontos que contribuíram muito no desenvolvimento da animação brasileira. Primeiro, o profissionalismo no setor e a criação de espaços na academia que ampliaram a ponto de existirem cursos técnicos e pós-graduação específicos para o segmento, como a Especialização em Animação em Mídias Digitais oferecida pelo curso de Design da Universidade Estadual de Londrina (UEL).

Em segundo vêm os incentivos público e privado que fomentam pesquisas, além de oferecer subsídios diretos para concretizar ótimas ideias que até então ficavam somente no papel. O principal exemplo é o Programa de Fomento à Produção e Teledifusão de Séries de Animação Brasileiras, conhecido como ANIMATV. Este projeto, similar ao DocTV (que fomenta a produção de documentários brasileiros) e igualmente bancado pelo Ministério da Cultura em parcerias com TVs educativas, tem como objetivo selecionar e custear animações por meio concursos públicos, divididos em diversos segmentos e orçamentos (do amador ao profissional).

Outro braço de atuação do ANIMATV é a pesquisa e a difusão de experiências e práticas por meio de eventos, encontros e publicações específicas para a área. O melhor exemplo dentre a safra de livros produzidos sobre o tema é a Dramaturgia de série de animação, de Sérgio Nesteriuk. Publicada em 2011, a edição é licenciada pelo sistema Creative Commons, portanto com acesso liberado via internet. ${ }^{1}$

Gratuito e com exatas 300 páginas, o livro abrange discussões sobre estética, estruturas de narrativa, discute o veículo de comunicação (a TV), apresenta o passo a passo para a criação e produção de uma animação (desde o argumento-base da série até sugestões de como apresentar projetos aos futuros parceiros e patrocinadores) e, por fim, elenca diversos exemplos de sucesso no exterior e também os da nova safra de desenhos surgidos no Brasil nos últimos cinco anos.

${ }^{1}$ Livro pode ser encontrado em diversos sites e blogs sobre Animação. Seguem dois links para acesso: http://blogs.cultura.gov.br/ANIMATV e http://animacaobrasileira.blogspot.com 
Munido de um grande repertório acadêmico (tem mestrado e doutorado em Comunicação e Semiótica pela PUC-SP) e conhecedor de todo o processo de produção de uma série animada, Sérgio Nesteriuk consegue equilibrar informações técnicas com apontamentos teóricos. Estão lá os debates sobre a indústria cultural de Adorno e Horkheimer, a reprodutibilidade técnica de Benjamim, detalhes sobre as primeiras narrativas visuais e as raízes da dramaturgia (as fábulas gregas de Esopo e a poética de Aristóteles), nomes de grandes historiadores da mitologia (como Joseph Campbell e Mircea Eliade), referências da tragédia e da comédia que sempre cercaram o imaginário coletivo.

Entre as páginas 25 e 41, o leitor encontra um ótimo passeio pelas animações produzidas em série para o cinema desde o final do século XIX, passando pelos respeitadíssimos estúdios de Walt Disney (criador de Mickey e Donald) e Warner Bros. Cartoons (de onde surgiram Pernalonga e Patolino) até as trilogias digitais de "Toy Story" e "A Era do Gelo" (esta última produção, aliás, dirigida pelo brasileiro que virou referência em Hollywood: Carlos Saldanha, o mesmo de "Rio").

Já no capítulo 2.2 (das páginas 72 a 118), há um detalhadíssimo resgate historiográfico das séries produzidas para a televisão, desde os anos dourados em que os estúdios Hanna-Barbera influenciaram sucessivas gerações (com Flintstones, Zé Colméia e Dom Pixote, entre dezenas de outras personagens) até a invasão dos animês japoneses e dos desenhos para adultos (onde Os Simpsons reinam há mais de 20 anos).

As discussões sobre a dramaturgia e a produção de roteiros começam no capítulo 3 (página 162), onde o autor esmiúça todas as etapas de construção da série antes mesmo de pensarmos no processo de animação. Ali estão dicas preciosas sobre como estruturar a narrativa da série (a construção das personagens, a story line, as sinopses comercial e técnica, o argumento, a escaleta, o roteiro e finalmente o story board). 
Encontram-se no livro tanto dicas técnicas - "uma personagem humana mais 'realista' tem entre oito e nove cabeças de altura" (pag. 195) - quanto conceituais: "é importante saber que projetos normalmente envolvem três dimensões inter-relacionadas, para as quais o roteirista de uma série de animação deve sempre atentar: tempo, escopo e recursos (humanos e financeiros)" (pág. 214).

Ainda sobre roteiro, capítulo de maior interesse deste resenhista, estão lá referências amplas (da "narratologia" do búlgaro Todorov aos manuais de roteiro do americano Syd Field e do brasileiro Doc Comparato) e específicas da produção do texto para o audiovisual, como o uso de spoilers - "descrições e revelações sobre o enredo, que são omitidas previamente do espectador" (pág. 206) - e a inserção de easter eggs, os detalhes que são identificados apenas pelos fãs que seguem uma série ("Tais elementos funcionam como uma espécie de gratificação para o espectador mais fiel” (pág. 213)).

Por fim, o último capítulo expõe detalhes do processo de seleção e produção dos projetos abarcados pelo ANIMATV. Nas considerações finais, Nesteriuk deixa 15 dicas para os interessados em adentrar o mundo da animação. Entre elas estão dois conselhos importantes: "Procure sempre expandir suas referências" e "Crítica, autocrítica e consultoria: saber procurar e escutar" (pág. 274).

Com tantos pontos favoráveis (a começar pelo fato de o texto ser um recurso eletrônico oferecido gratuitamente), esta obra merece ser difundida para profissionais e estudantes das mais diversas áreas. Ali estão debates importantes que envolvem muito mais que desenho animado: é o próprio processo de formação e educação das gerações surgidas já imersas na comunicação audiovisual. Condição curiosamente já observada por Aristóteles 350 anos antes de Cristo: "A alma nunca pensa sem uma imagem", escreveu o filósofo macedônio no tratado De Anima, a palavra grega para alma.

Anima... Ação... O termo seria, portanto, dar alma (vida, ação) aos textos e aos personagens sonhados pelos criadores? No livro $A$ linguagem secreta do cinema (Editora Nova Fronteira, 2006, p.131), 
Jean-Claude Carriére responde esta questão com uma frase singular: "Realizar um filme é verdadeiramente um trabalho de alquimia, de transmutar papel [roteiro] em filme. Transformar a própria matéria." 